\title{
We can design too: an insight with a group of students at Universiti Putra Malaysia
}

\begin{abstract}
This study investigates to what extent a group of studentsô involvement in creating and designing storyboard tasks affects their motivation towards learning English. The study applies the qualitative approach. 20 subjects of ages between 18-20 year old were picked at random from two classes of BBM 3410 (Malay Language and Multimedia). They were interviewed by referring the motivation inventories to complete before and after an intervention project which involves creating and designing storyboard tasks. The experimental group participated in sixteen sessions of storyboard writing over fourteen weeks. This research also focuses on the processes the experimental group were engaged in creating and designing learning materials using a storyboard computer programme. This part investigates the content of discussion which occurred while they were storyboarding. Transcriptions of their video-recorded interactions, as well as diaries and motivation graphs completed by the subjects were analysed and coded accordingly. Findings of the study suggest that the storyboard writing project enhanced their motivation and perceived as a valuable learning method.
\end{abstract}

Keyword: Motivation; Storyboard writing 